\title{
Direct Vision Internal Urethrotomy (DVIU) and Regular Clean Self Intermittent Catheterization (CSIC) For Short Bulbar Urethral Strictures: A Durable Solution
}

\author{
Pankaj Trivedi ${ }^{\odot}$ \\ Assistant Professor, Department of Urology, Geetanjali Medical College \& Hospital, Udaipur, Rajasthan, India.
}

\section{Abstract}

Background: To evaluate durability of DVIU results and recurrence of stricture if the CSIC was done regularly up to one year and weekly thereafter. Subjects and Methods: This retrospective study was conducted in the Department of Urology at tertiary care teaching hospital of Rajasthan, India. Files of all patients operated between January 2015 and July 2018 for single bulbar urethral strictures of less than 1-1.5cm size in length, iatrogenic, idiopathic, traumatic or inflammatory origins were evaluated. Patient with multiple or complicated strictures of post urethroplasty, post hypospadias repair, previous radiation or multiple DVIU were excluded from the study. Data of all patients who were on CSIC following direct vision internal urethrotomy were evaluated at 3, 6, 12 and 24 months. Results: Mean age of patients was 41.13 years with range in between 26-74 years. Most common cause of urethral strictures were idiopathic 66 (58.92\%) followed by iatrogenic 27 (24.11\%) causes. After 24 months of follow up 95 (84.82\%) patients maintained urethral caliber up to 16 Fr. Failure or recurrence was found in 17 (15.18\%) patients who required intervention. Conclusion: Direct vision internal urethrotomy (DVIU) with regular clean intermittent self-catheterization (CSIC) was found good success rate in bulbar urethral strictures upto $1 \mathrm{~cm}$ in selected patients.

Keywords: Clean Self-Intermittent Catheterization, Direct Vision Internal Urethrotomy, Urethral Strictures, Recurrence

Corresponding Author: Pankaj Trivedi, Assistant Professor, Department of Urology, Geetanjali Medical College \& Hospital, Udaipur, Rajasthan, India.

E-mail: drpankajtrivedi@rediffmail.com

Received: 14 September $2020 \quad$ Revised: 29 October 2020

Accepted: 11 November 2020

Published: 27 December 2020

\section{Introduction}

Anterior urethral stricture refers to scarring of corpus spongiosum which result in narrowing of urethral lumen. Urethral strictures are encountered in routine practice of urologist. [1] Common etiological factors for this are trauma, infection, inflammatory processes, iatrogenic urethral manipulations and idiopathic. Straddle injury, penetrating injury, gonococcal urethritis, lichen sclerosis, prostatic surgeries, urethral catheterization and instrumentation, previous hypospadias surgery are well known causes of urethral strictures. ${ }^{2]}$ Patients usually present with voiding symptoms, dysuria, recurrent urinary tract infections (UTI). Severe cases may present with urinary retention, bladders stones or obstructive nephropathy. ${ }^{[3]}$

Treatment option includes urethral dilation, direct vision internal urethrotomy (DVIU) or open urethroplasty procedures. DVIU and dilatation are most commonly performed minimal invasive procedure for urethral strictures because of its advantages of simplicity, low cost, minimal complications, short hospitalization and recovery time. Dilatation has high recurrence rates whereas urethroplasty surgery is complex, demanding good surgical skills, high cost and with long recovery time. ${ }^{[4]}$

Recurrence is the most common complication of DVIU. Despite the initial good results in initial studies, recent studies show poor long-term success of DVIU. The concept of clean self-intermittent catheterization (CSIC) after DVIU was introduced into 1980's. ${ }^{5]}$ Lawrence and McDonagh have concluded that low friction self-catheterization after DVIU is very satisfactory method of managing patients with recurrent strictures. ${ }^{[6,7]}$ Kjaegarrd et al have studied 55 patients and concludes that weekly CSIC is a simple method of reducing recurrence of strictures after DVIU. ${ }^{[8]}$

Various studies have conducted worldwide having different conclusions but on literature search very few studies were found from India. This study was planned to evaluate durability of DVIU results and recurrence of stricture if the CSIC was done regularly up to one year and weekly thereafter. 


\section{Subjects and Methods}

This retrospective study was conducted at tertiary care teaching hospital of Rajasthan, India, only after taking approval from Human Research Ethics Committee of institute. Files of all patients operated for bulbar urethral strictures between January 2015 to July 2018 were evaluated. As per study protocol only single bulbar stricture less than 1$1.5 \mathrm{~cm}$ size in length, iatrogenic, idiopathic, traumatic or inflammatory origins were included. Urethroplasty surgery was offered to the indicated patients. Those who refused were taken into the study. Patient with multiple or complicated strictures of post urethroplasty, post hypospadias repair, previous radiation or multiple DVIU were excluded from the study. Before contemplating procedure, patients were thoroughly explained about nature of disease and its recurrence potential. They were counseled about regular passage of clean self-intermittent cauterization (CSIC) for at least 2 years or life time if required. They were motivated to make it part of daily routine like brushing teeth, cleaning body parts to avoid recurrence of disease.

After initial evaluation of stricture through 6/7.5 Fr Wolf Ureteroscope, guidewire placed through urethra into urinary bladder. Then a standard technique of Direct Vision Internal Urethrotomy (DVIU) using Sachse's knife with $21 \mathrm{Fr}$ Urethrotome sheath was used. A single 12 o'clock incision was given to divide the full thickness of scar tissue until Urethrotome sheath goes freely into bladder. 20 Fr Foley catheter passed over guide wire. Patients were usually discharged on next day and catheter was kept for 7 to 10 days.

After catheter removal patients were instructed to do CSIC with 18 Fr Foley daily for 3 months then alternate day for next 3 months and then twice a week there after up to one year. After one year of regular CSIC they were asked to do it weekly. All patiently were first followed after 3 weeks, then 3 monthly up to 1 year and 6 monthly thereafter. On follow up symptoms related to flow, any difficulty in CSIC and urinary tract infection were asked. Uroflowmetery was done in all patients 6 monthly in first year and yearly thereafter. All patients were followed up to 24 months.

During follow-up if patients complained of unable to pass 18 Fr Foley but happy with urinary stream and uroflow was more than $15 \mathrm{ml} / \mathrm{sec}$ then they were switched to $16 \mathrm{Fr}$ Foley. If flow rates were less than $15 \mathrm{ml} / \mathrm{sec}$ or unable to pass $16 \mathrm{Fr}$ Foley then DVIU was considered failure and retrograde urethrogram (RGU) was advised and further definitive treatment was planned.

The obtained data was expressed in number and percentage. Suitable statistical test was used to analyze the data.
Results

From January 2015 to July 2018 total 152 patients underwent DVIU. 131 patients having single bulbar urethral stricture were included in study and 19 patients lost to follow up. Finally we analyzed the data of 112 patients who had completed 24 months of follow up. [Figure 1]

Mean age of patients was 41.13 years with range in between 26-74 years. Causes of stricture were idiopathic in $66(58.92 \%)$, inflammatory in $15(13.39 \%)$, iatrogenic (post catheterization, post TURP, previous dilatation) in 27 $(24.11 \%)$ and traumatic in $04(3.57 \%)$ patients. Location of stricture was proximal bulbar in $18(16.07 \%)$, midbulbar in $58(51.79 \%)$ and distal bulbar in $36(32.14 \%)$ patients. In 99 $(88.39 \%)$ patients stricture was $<1 \mathrm{~cm}$ in length and in 13 $(11.61 \%)$ patients it was between $1-1.5 \mathrm{~cm}$. [Table 1]

\begin{tabular}{|l|l|}
\hline \multicolumn{2}{|c|}{ Table 1: Baseline characteristics of all the patients (n=112) } \\
\hline $\begin{array}{l}\text { Mumber (\%) } \\
\text { Eean age (years) }\end{array}$ & 41.13 (range 26-74) \\
\hline Idiopathic & $66(58.92 \%)$ \\
\hline Inflammatory & $15(13.39 \%)$ \\
\hline Traumatic & $04(3.57 \%)$ \\
\hline Iatrogenic & $27(24.11 \%)$ \\
\hline Stricture size & \\
$<1$ cm (short bulbar) & $99(88.39 \%)$ \\
\hline 1 to $1.5 \mathrm{~cm}$ & $13(11.61 \%)$ \\
\hline Site of stricture & \\
\hline Proximal bulbar & $18(16.07 \%)$ \\
\hline Mid bulbar & $58(51.79 \%)$ \\
\hline Distal bulbar & $36(32.14 \%)$ \\
\hline
\end{tabular}

All 112 patients were first kept on 18 Fr CSIC. 71 switched over to $16 \mathrm{Fr}$ within 3 months due to difficulty in CSIC with $18 \mathrm{Fr}$. Overall, at the end of 12 months, 37 were doing CSIC using $18 \mathrm{Fr}, 67$ with $16 \mathrm{Fr}$ and 8 required interventions. After 24 months 95 (84.82\%) patients maintained caliber above 16 Fr catheter and $17(15.18 \%)$ required intervention. [Table 2]

Out of these 17 patients, 9 were having stricture length $>1$ $1.5 \mathrm{~cm}, 3$ were of traumatic origin, 4 iatrogenic, 4 inflammatory and 6 were of idiopathic etiology. During the period of 2 years, 19 developed urinary tract infection and 3 had epididymoorchitis requiring intravenous antibiotics. [Table 3)]

\section{Discussion}

Internal urethrotomy is transurethral procedure of incision through scar tissue to healthy tissue in corpus spongiosum. 
Table 2: Attrition on clean self-intermittent catheterization(CSIC) and failures $(n=112)$

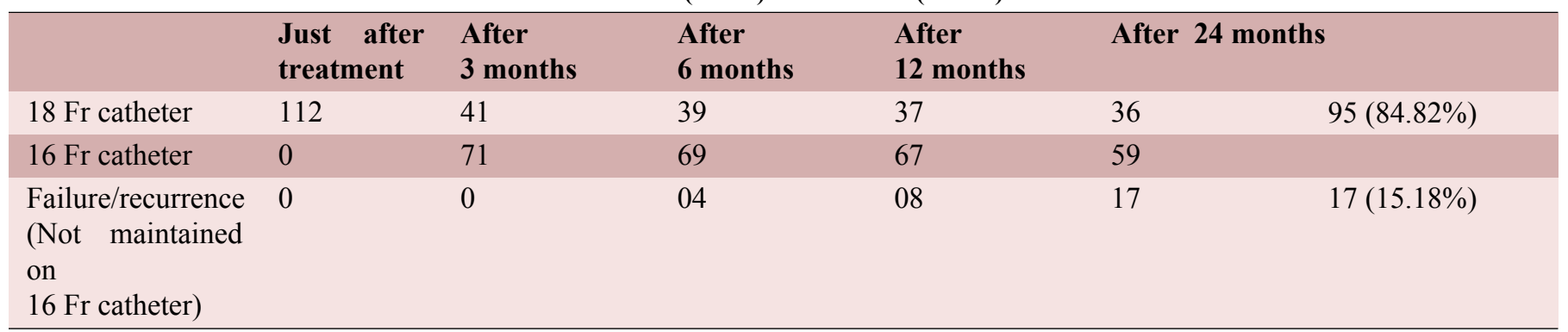

Table 3: Causes of failure/recurrence in patients

\begin{tabular}{ll}
\hline Etiology & Number of patients $(\%)$ \\
Idiapathic $(n=66)$ & $06(9.09 \%)$ \\
Inflammatory $(n=15)$ & $04(26.67 \%)$ \\
Traumatic $(n=4)$ & $03(75 \%)$ \\
Iatrogenic $(n=27)$ & $04(14.81 \%)$ \\
Stricture $>1 \mathrm{~cm}(\mathrm{n}=13)$ & $09(69.23 \%)$ \\
\hline
\end{tabular}

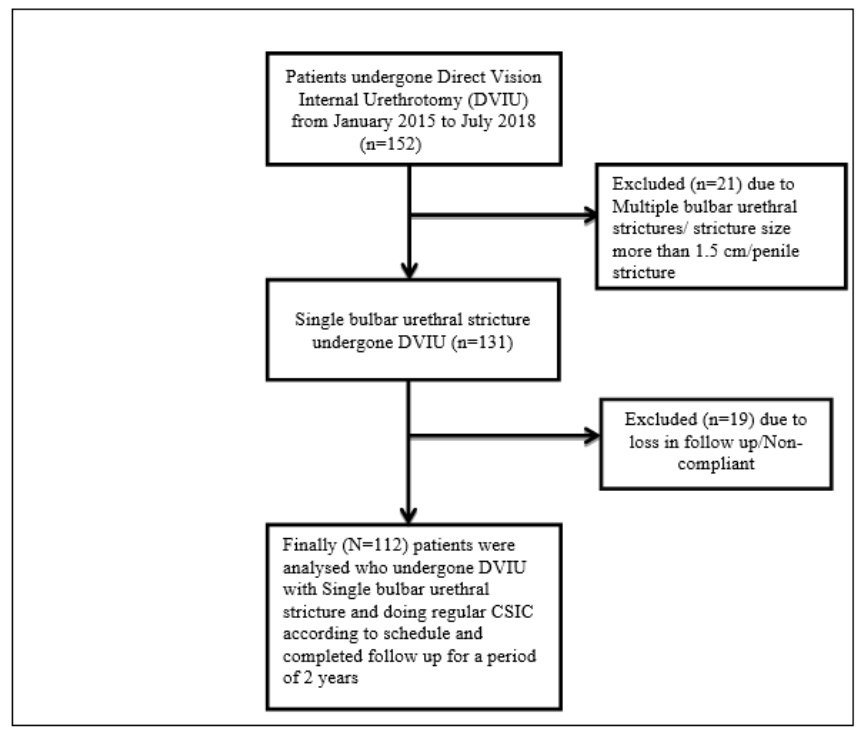

Figure 1: Study Flowchart

DVIU was initially used by Sachse in 1974, is still the most commonly performed procedure for stricture urethra. ${ }^{6]}$

Lawrence and McDonagh have reported that all 42 patients included in their study; on low friction self-catheterization after DVIU were able to pass catheter satisfactorily and maintained flow rates. Roosen concluded CSIC is promising preventive measure for stricture recurrence as 19 patients out of 29 in their study regularly done CSIC and had maintained significantly improved flow rates. ${ }^{[9]}$ Studies done by Kjaergaard et al and Lauritzen et al have also found that CSIC group developed significantly less recurrence as compared to non- CSIC (control) group after follow up. ${ }^{[8,10]}$ In present study $84.82 \%$ patients were able to maintained flow more than $15 \mathrm{ml} / \mathrm{sec}$ after clean self-intermittent cathertization (CSIC) using 16 Fr catheter. Recurrence of strictures in present study were found in $15.18 \%$ patients. These patients required intervention in the form of either urethroplasty or repeat DVIU.

One study has reported that simple urethral dilation for recurrent bulbo membranous urethral strictures has significantly less recurrence rate. ${ }^{[11]}$ Systemic review and Meta-analysis done in 2014 and 2016 respectively have reported that intermittent self-dilatation may confer a reduced risk of recurrence of urethral stricture recurrence. ${ }^{[12,13]}$

Urethral stricture size more than $1 \mathrm{~cm}$ in length out of all recurrence patients was found in $52.94 \%$ patients in present study. Similar results were in many studies in which they have found more recurrence in patients having stricture size more than $1 \mathrm{~cm} .{ }^{[4,5,7]}$ This proves that large stricture length is responsible for more recurrence rate.

Pansadoro et al found recurrence rate $84 \%$ for penile strictures. ${ }^{[14]}$ In present study $15.16 \%$ recurrence rate may also be due to the fact that the present study included only patients of bulbar urethral strictures which shows good success rate because of well vascularized part.

In our study $75 \%$ patients of traumatic origin were found to have recurrence as compared to other causes. Nielsen et al found patients of inflammatory and traumatic strictures have less recurrence then iatrogenic and infective etiology. ${ }^{[15]}$ There are no consensuses about cause of recurrence and etiology as different studies have different conclusion about etiology and its role in recurrence.

In present study old age patient's acceptance and compliance were found better and they had good perception about quality of life with weekly CSIC. Greenwell et al in 2004 suggested the strategy of dilation/ initial urethrotomy followed by urethroplasty in recurrent stricture is most cost effective. ${ }^{[16]}$ 


\section{Conclusion}

The present study concluded that good direct vision internal urethrotomy (DVIU) followed by regular clean intermittent self-catheterization (CSIC) is durable and cost effective method in compliant and selected patients.

\section{References}

1. Stein MJ, Desouza RA. Anterior urethral stricture review. Transl Androl Urol. 2013;2(1):32-38. Available from: https: //dx.doi.org/10.3978/j.issn.2223-4683.2012.11.05.

2. Alwaal A, Blaschko SD, Mcaninch JW, Breyer BN. Epidemiology of urethral strictures. Transl Androl Urol. 2014;3(2):209213. Available from: https://dx.doi.org/10.3978/j.issn.22234683.2014.04.07.

3. Bergamin PA, Kiosoglous AJ. Surgical management of recurrent urinary tract infections: a review. Transl Androl Urol. 2017;6(S2):S153-S162. Available from: https://dx.doi.org/10. 21037/tau.2017.06.17.

4. Pal D, Kumar S, Ghosh B. Direct visual internal urethrotomy: Is it a durable treatment option? Urol Ann. 2017;9(1):18-18. Available from: https://dx.doi.org/10.4103/0974-7796.198835.

5. Dubey D. The current role of direct vision internal urethrotomy and self-catheterization for anterior urethral strictures. Indian $\mathrm{J}$ Urol. 2011;27(3):392-398. Available from: https://doi.org/10. 4103/0970-1591.85445.

6. Lawrence WT, MacDonagh RP. Treatment of Urethral Stricture Disease by Internal Urethrotomy followed by Intermittent 'Low-Friction' Self-Catheterization: Preliminary Communication. J ROY SOC MED. 1988;81(3):136-139. Available from: https://dx.doi.org/10.1177/014107688808100306.

7. Zehri AA, Ather MH, Afshan Q. Predictors of recurrence of urethral stricture disease following optical urethrotomy. Int J Surg . 2009;7(4):361-364. Available from: https://dx.doi.org/ 10.1016/j.ijsu.2009.05.010.

8. Kjaergaard B, Walter S, Bartholin J, Andersen JT, Nohr S, Beck $\mathrm{H}$, et al. Prevention of urethral stricture recurrence using clean intermittent self-catheterization. Br J Urol. 1994;73(6):692695. Available from: https://dx.doi.org/10.1111/j.1464-410x. 1994.tb07558.x.

9. Roosen JU. Self-Catheterization after Urethrotomy. Urol Int. 1993;50(2):90-92. Available from: https://dx.doi.org/10.1159/ 000282459.

10. Lauritzen M, Greis G, Sandberg A, Wedren H, Öjdeby G, Henningsohn L. Intermittent self-dilatation after internal urethrotomy for primary urethral strictures: A case-control study. Scand J Urol Nephrol. 2009;43(3):220-225. Available from: https://dx.doi.org/10.1080/00365590902835593.

11. Tunc M, Tefekli A, Kadioglu A, Esen T, Uluocak N, Aras N. A prospective, randomized protocol to examine the efficacy of postinternal urethrotomy dilations for recurrent bulbomembranous urethral strictures. Uro. 2002;60(2):239-244. Available from: https://dx.doi.org/10.1016/s0090-4295(02)01737-5.

12. Jackson MJ, Veeratterapillay R, Harding CK, Dorkin TJ. Intermittent self-dilatation for urethral stricture disease in males. Cochrane Database Syst Rev. 2014;19(12):1025810258. Available from: https://doi.org/10.1002/14651858. cd010258.pub2.

13. Ivaz SL, Veeratterapillay R, Jackson MJ, Harding CK, Dorkin $\mathrm{TJ}$, Andrich DE, et al. Intermittent self-dilatation for urethral stricture disease in males: A systematic review and metaanalysis. Neurourol Urodyn. 2016;35(7):759-763. Available from: https://dx.doi.org/10.1002/nau.22803.

14. Pansadoro V, Emiliozzi P. Internal Urethrotomy in the Management of Anterior Urethral Strictures: Long-Term Followup. J Urol. 1996;156(1):73-75. Available from: https://dx.doi.org/ 10.1016/s0022-5347(01)65942-1.

15. Holm-Nielsen A, Schultz A, Møller-Pedersen V. Direct Vision Internal Urethrotamy. A Critical Review of 365 Operations. Br J Urol. 1984;56(3):308-312. Available from: https://dx.doi. org/10.1111/j.1464-410x.1984.tb05393.x.

16. Greenwell TJ, Castle C, Andrich DE, MacDonald JT, Nicol DL, Mundy AR. Repeat Urethrotomy and Dilation for the Treatment of Urethral Stricture Are neither Clinically Effective nor CostEffective. J Urol . 2004;172(1):275-277. Available from: https://dx.doi.org/10.1097/01.ju.0000132156.76403.8f.

Copyright: (C) the author(s), 2020. It is an open-access article distributed under the terms of the Creative Commons Attribution License (CC BY 4.0), which permits authors to retain ownership of the copyright for their content, and allow anyone to download, reuse, reprint, modify, distribute and/or copy the content as long as the original authors and source are cited.

How to cite this article: Trivedi P. Direct Vision Internal Urethrotomy (DVIU) and Regular Clean Self Intermittent Catheterization (CSIC) For Short Bulbar Urethral Strictures: A Durable Solution. Acad. J Surg. 2020;3(2):13-16.

DOI: dx.doi.org/10.47008/ajs/2020.3.2.4

Source of Support: Nil, Conflict of Interest: None declared. 